\title{
Design of equipment for mas-wrestling
}

\author{
Lyubov Zhukova ${ }^{1, *}$, and Diana Baisheva ${ }^{1}$ \\ ${ }^{1}$ Saint-Petersburg State University of Industrial Technologies and Design, Bolshaya Morskaya str., \\ 18, St. Petersburg, 191186, Russia
}

\begin{abstract}
The present research considers the elaboration of an item of sports equipment - a stick for mas-wrestling. The paper describes the design process of this equipment taking into account physical and mechanical properties and material roughness, as well as sportsmen's anthropometry parameters according to their weight category. A classification of sportsmen by anthropometry indicators was elaborated, that contains three groups and provides for age groups. The material to produce the equipment for mas-wrestling was chosen based on a comparative analysis of physical and mechanical properties of materials.
\end{abstract}

\section{Introduction}

Mas-wrestling is one of national sports of the peoples of Yakutia, currently gaining popularity not only in Russia but also abroad. In 2000, mas-wrestling was included into the program of the International Sports Games "Children of Asia", which are under protection of the International Olympic Committee. July 16, 2003 is deemed to be a starting point of the development of mas-wrestling, since it was included into the All-Russian Register of Sports as a national sport by the order № 546 of the State Sports Committee of the Russian Federation. On June 27, 2005, the federal registration service of the Ministry of Justice of Russia registered an All-Russian Public Organization "All-Russian Mas-Wrestling Federation" (ARMF) and included it into the Unified State Register of legal entities. ARMF is a member of the International Mas-Wrestling Federation involving 49 countries and ranks a leading position there. This kind of combat sport is planned to have been included into the program of the Olympic Games by 2036 [13].

While seeming so simple and unpretentious, mas-wrestling helps athletes develop comprehensively and harmoniously, because all muscle groups are involved in a combat (RF Patent 147698 U1, IPC A63B 71/04). Mas-wrestlers who systematically work out, have a well-built muscle core that is able to withstand significant loads during a simplelooking combat [8].

The production of mas-wrestling equipment and providing it to gyms is under constant control of state power institutions of Yakutia, which indicates the relevance of equipment production. Requirements for equipping and placing training classes and competition halls are determined by certain rules. All inventory and equipment should have certificates of conformity with State Standard GOST. Technical conditions for equipment production are

* Corresponding author: 1t_zhukova@mail.ru 
also prescribed. The equipment used in this sport is a stick. According to its technical, operational and other characteristics, the equipment should provide the necessary level of organization of training and competitive activity at all levels from republican to international [2]. According to international rules of mas-wrestling, the stick is made of birch or other solid wood, it is cylindrical, has center marking with width of $10 \mathrm{~mm}$ and the following dimensions: length is $40-50 \mathrm{~cm}$, diameter is $34 \mathrm{~mm}( \pm 1 \mathrm{~mm})$, as shown in figure $1^{\dagger}$. The stick can be reinforced with a metal core, but its surface has to be wooden. The weight of the stick is $400-450 \mathrm{~g}$. In all official competitions, the equipment must be certified by the IMF.

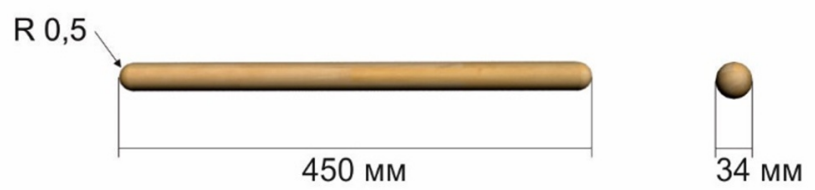

Fig. 1. Equipment - stick for mas-wrestling TU 9616-001-97548408-2013

In Russia, sticks are made of birch without coating, waxing or processing with antiseptic compounds, wood stain or other finishing materials and in accordance with RF Specification TU 9616-001-97548408-2013 developed in 2013 by the Center of National Sports of the Republic of Sakha (Yakutia) named after Vasily Manchaara. Other countries use different timber species to make equipment for mas-wrestling, for example, in Azerbaijan it is oak, in India - amaranth, in Georgia - linden, in Turkey - hazel-wood. (Pat. CN206642294 (U), CPC (IPC) A63B23/16; Pat. US2015182829 (A1), CPC (IPC) A63B59/20, A63B60/00, A63B60/16, A63B60/28, A63B2102/14, A63B2102/24, A63B60/50; Pat. CN205988510 (U), CPC (IPC) A63B21/072). However, the equipment used for mas-wrestling has not changed in its design or size and was not comparatively analyzed in terms of physical and mechanical and aesthetic characteristics. The diameter of sticks for any competitions between boys, girls, male and female juniors and male and female veterans is $34 \mathrm{~mm}$.

This work is focused on the process of designing equipment based on a comparative analysis of physical and mechanical properties of wood, taking into account the classification of weight categories of sportsmen by anthropometric parameters.

The present study is dedicated to the development of sports equipment - a stick for maswrestling. Tug of a stick - mas-wrestling -has been gaining more and more popularity around the world in recent years $[1,5]$. The number of states moving forward with maswrestling as a promising combat sport is growing. Constant attention payed by the sports society to the issue of expanding the range of equipment for mas-wrestling is caused by the inclusion of mas-wrestling in the list of summer Olympic sports in 2036 (RF Patent 156973 U1, IPC A63B71/04). The paper presents the process of designing the equipment - a stick for mas-wrestling taking into account physical and mechanical properties and roughness indices of materials for sticks and anthropometric parameters of athletes by weight category. The classification of athletes by anthropometric parameters was worked out. Group 1 includes athletes with a height of up to $1.68 \mathrm{~m}$ belonging to the weight categories of 40, 50, 55 and $60 \mathrm{~kg}$ in different age groups. Group 2 involves athletes of height from

\footnotetext{
$\dagger$ International rules on mas-wrestling, approved by the IMF Congress on November 24, 2012 in Moscow, Russia. Amendments and additions were made on December 12, 2013 in Dubai, the United Arab Emirates; November 27, 2015 in Moscow, the Russian Federation; September 04, 2016 in Cholpon-Ata, Kyrgyzstan; December 16, 2017 in Moscow, the Russian Federation; November 24, 2018 in Yakutsk, the Russian Federation (24 pp. III. 42 p.)
} 
1.68 to $1.8 \mathrm{~m}$ belonging to weight categories of $60,70,75,80$ and $85 \mathrm{~kg}$ in different age groups. Group 3 is for athletes who is $1.8 \mathrm{~m}$ high and above belonging to weight categories of $90,105,125$ and $125+\mathrm{kg}$ in different age groups. For each group, the average width and length of sportsmen's hands, back strength and hand's strength were determined. The stick diameter was calculated for three groups of athletes in accordance with their anthropometric data.

The purpose of a technical solution is to improve the design in order to better aesthetic and ergonomic properties of the stick and reduce injuries during competitions and training classes.

\section{Materials and methods}

Methods. The choice of material for production of mas-wrestling equipment was substantiated through comparative analysis of physical and mechanical properties of materials [3, 4, 10, 11] of sticks TU 9616-001-97548408-2013 made of birch, oak, amaranth, linden and hazel wood and produced in the following countries: Azerbaijan, India, Georgia and Turkey, respectively. Those sticks were used at the following International competitions: the 1st series of the Mas-Wrestling World Cup in the Republic of Kazakhstan, Almaty, April 29-30, 2017; the 2nd series of the Mas-Wrestling World Cup in Hungary, Gyor, November 4-5, 2017; the 3rd series of the Mas-Wrestling World Cup in Russia, Moscow, December 16-17, 2017. In total, 7 men's weight categories: 60, 70, 80, $90,105,125$ and over $125 \mathrm{~kg}$, and 5 women's weight categories: 55, 65, 75, 85 and over 85 $\mathrm{kg}$, were studied. 20 sticks were used in each weight category. Mechanical damages to equipment were recorded: splits, breaks, as well as stains of magnesia and natural secretions of human body running under high loads [6]. Calculation of stick's diameter for each group of athletes was carried out on the basis of the theory of material resistance, considering a pure bending of a beam as the main deformation $[7,12]$.

The systematic approach served as a methodological basis. Mas-wrestling sticks TU 9616-001-97548408-2013, made of birch, oak, amaranth, linden and hazel wood, produced in Azerbaijan, India, Georgia and Turkey respectively, were examined during the following International competitions: the 1st series of the Mas-Wrestling World Cup in the Republic of Kazakhstan, Almaty, April 29-30, 2017; the 2nd series of the Mas-Wrestling World Cup in Hungary, Gyor, November 4-5, 2017; the 3rd series of the Mas-Wrestling World Cup in Russia, Moscow, December 16-17, 2017. Totally 7 men's weight categories were studied: $60,70,80,90,105,125$ and over $125 \mathrm{~kg}$, as well as 5 women's weight categories: 55, 65, 75,85 and over $85 \mathrm{~kg}$. In each weight category 20 sticks were used. The mechanical damage to sticks were recorded: splits, breaks, as well as stains of magnesia and natural secretions of the human body running under high loads.

\section{Results and analysis}

During training process and competitions, a large number of mechanical damages to the equipment was detected, for instance, breaks of sticks that can lead to injuries got by athletes. This work presents studies determining the number of damages to sticks of birch at three series of the 2017 Mas-Wrestling World Cup for weight categories among men 60, $70,80,90,105,125$ and over $125 \mathrm{~kg}$, as well as 5 weight categories among women: 55, 65, 75,85 and over $85 \mathrm{~kg}$. Each category implied 20 fights, sticks were replaced after each combat. The research results are presented in fig 2 .

The analysis of the research results presented in Figure 1 showed that in the men weight categories of $90,105,125$ and over $125 \mathrm{~kg}$, the number of equipment damage is more than 
in small weight categories by $20-25 \%$, while among women of 75,85 and over $85 \mathrm{~kg}$ it is more by $10-15 \%$. Therefore, a comparative analysis of the inventory made of various materials was conducted: birch, oak, amaranth, linden and hazel wood in terms of physical and mechanical properties, taking into account anthropometric parameters of the athletes.

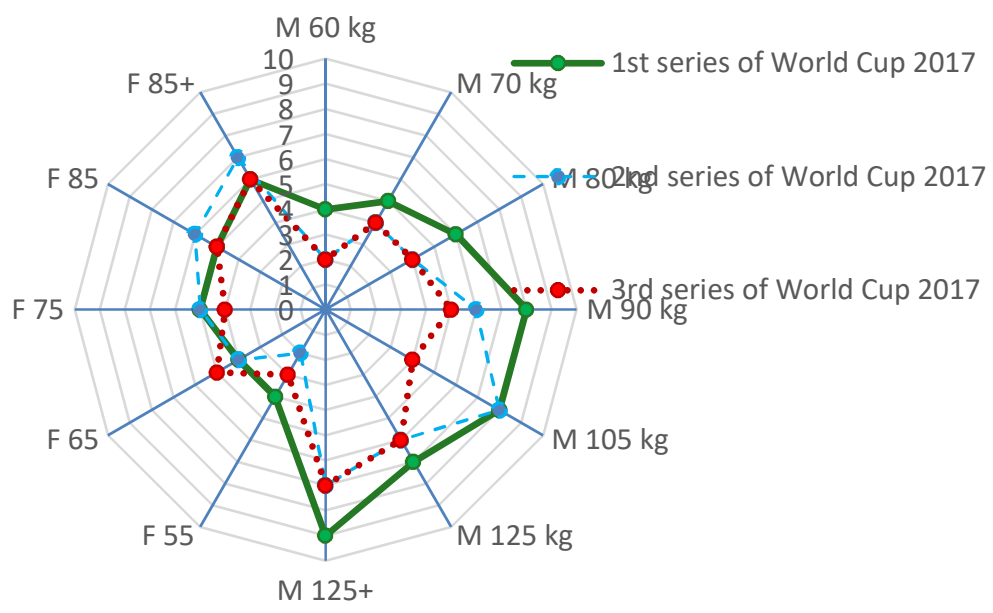

Fig. 2. Number of damage to equipment - sticks TU 9616-001-97548408-2013 in men weight categories of $60,70,80,90,105,125$ and over $125 \mathrm{~kg}$, women weight categories of 55, 65, 75, 85 and over $85 \mathrm{~kg}$ at 3 series of Mas-Wrestling World Cup 2017

Physical and mechanical properties of wood are presented in Table 1. The comparative analysis of physical and mechanical parameters of mas-wrestling sticks made of birch, oak, amaranth, linden and hazel wood educed that a stick made of birch outperforms in all respects.

Amaranth has the highest elastic modulus equaling $16.3 \mathrm{GPa}$. The bending modulus of birch is $14.2 \mathrm{GPa}$. However, the density of amaranth wood is higher than that of birch, which impacts the weight of the equipment. The density of birch is $640 \mathrm{~kg} / \mathrm{m}^{3}$, the density of amaranth is $880 \mathrm{~kg} / \mathrm{m}^{3}$, so the weight of a birch stick is $27.3 \%$ less than the weight of an amaranth stick.

Moreover, athletes of lightweight categories often have controversial moments when a stick hits the rest-board with its ends, so that one of the athletes can tug it by the "lever method", which is forbidden by the competition rules, so the athlete gets penalty point.

An athlete with two penalty points is considered a loser. This can be explained by the length of a stick which is the same for all categories of athletes in accordance with the rules of a competition, therefore it is concluded that anthropometric characteristics are not taken into account. The only size of sticks established according to TU 9616-001-97548408-2013 (length $-450 \mathrm{~mm}$, diameter $-34 \mathrm{~mm}$ ) does not correspond to anthropometric parameters of all categories of athletes.

Improper equipment entails the development of completely wrong skills during training of lightweight category athletes - young boys and girls. Figure 3 represents the comparison of hand grips of two athletes. 
Table 1. Physical and mechanical properties of materials for mas-wrestling sticks [6]

\begin{tabular}{|c|c|c|c|c|c|c|c|c|c|c|c|}
\hline \multirow{3}{*}{ 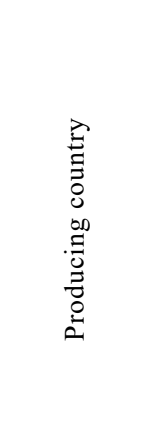 } & \multirow[b]{3}{*}{ 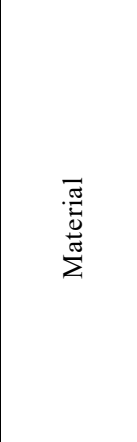 } & \multirow[b]{3}{*}{ 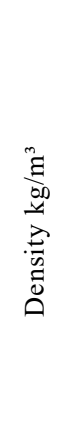 } & \multicolumn{5}{|c|}{ Strength limit, $\mathrm{MPa}$} & \multirow{2}{*}{\multicolumn{3}{|c|}{ Hardness, HB }} & \multirow{3}{*}{ 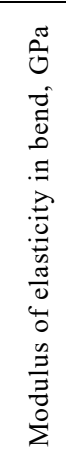 } \\
\hline & & & \multirow[b]{2}{*}{ 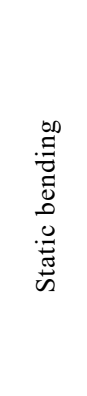 } & \multirow{2}{*}{ 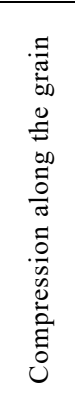 } & \multirow{2}{*}{ 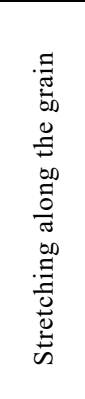 } & \multicolumn{2}{|c|}{$\begin{array}{c}\text { Shear } \\
\text { parallel to } \\
\text { the grain }\end{array}$} & & & & \\
\hline & & & & & & 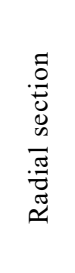 & 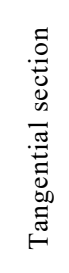 & 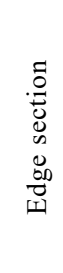 & 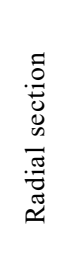 & 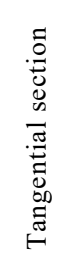 & \\
\hline Russia & Birch & 640 & 109.5 & 54.0 & 136.5 & 9.02 & 10.9 & 46.3 & 35.9 & 32.1 & 14.2 \\
\hline Azerbaijan & Oak & 780 & 87.3 & 55.9 & 117.8 & 10.7 & 12.7 & 57.3 & 48.2 & 52.8 & 12.2 \\
\hline India & Amaranth & 880 & 148 & 73.1 & 171 & 13.2 & 14.7 & 94.2 & 66.2 & 75.9 & 16.3 \\
\hline Georgia & Linden & 495 & 86.4 & 45.8 & 117 & 8.42 & 8 & 25 & 16.7 & 17.4 & 8.94 \\
\hline Turkey & Hazel & 590 & 108 & 55.4 & - & 10.7 & 11.4 & 62 & - & - & 11.7 \\
\hline
\end{tabular}

L

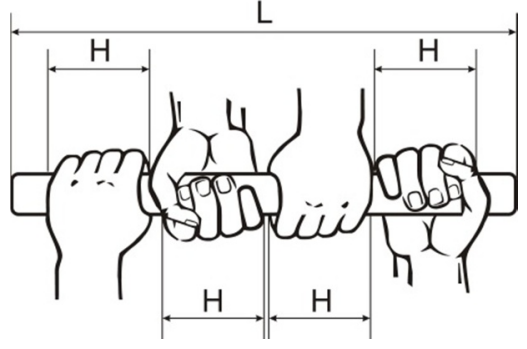

Fig. 3. The comparison of width of hand grips of two athletes: $\mathrm{N}$ - width of a hand, taking into account the base of a thumb; L - stick length

To make an ergonomic design of a stick for mas-wrestling, a classification of athletes by anthropometric parameters was elaborated (Figure 4). An athlete's height indicator includes a $25 \mathrm{~mm}$ allowance for the height of a shoe sole. Athletes of all age groups and weight categories are divided into 3 groups by anthropometric parameters [14]:

Group 1 - athletes of up to $1.68 \mathrm{~m}$ high belong to weight categories of 40, 50, 55 and 60 $\mathrm{kg}$ in different age groups.

Group 2 - athletes of height from 1.68 to $1.8 \mathrm{~m}$ belong to weight categories of 60,70 , 75,80 and $85 \mathrm{~kg}$ in different age groups.

Group 3 - athletes of height from $1.8 \mathrm{~m}$ and above belong to weight categories of 90 , 105,125 and $125+\mathrm{kg}$ in different age groups.

For each group, the athlete's average hand width and length were determined, back strength and hand strength are presented in Figure 7.

Length values of a stick were calculated taking into account a gap of $10 \mathrm{~mm}$ between hands of two athletes and a distance of $20 \mathrm{~mm}$ from each end of a stick. Length values were taken 450, 500 and $550 \mathrm{~mm}$ respectively for the 1st, 2nd and 3rd group of athletes.

The stick diameter was calculated for three groups of athletes in accordance with their anthropometric data. The proper strength of the stick will be ensured if its diameter $d$ is greater than a certain diameter $d_{\text {min }}$, which is determined according to the rules of the 
theory of material resistance. To calculate $d_{\text {min }}$, anthropometric data presented in Figure 6 were used: width values of hands for 12 categories of wrestlers and the corresponding values of back strength. Hand width is further denoted by $H$, back strength is taken equaling $2 P$, where $P$ is the pulling force of one hand.

The length of the stick is indicated by $L$, the standard gap between a hand and an end of the stick is denoted by $g=20 \mathrm{~mm}$, the gap between hands gripping the stick is $h=10 \mathrm{~mm}$. The standard stick loading pattern is considered with taking into account these gaps, as shown in Figure 4.

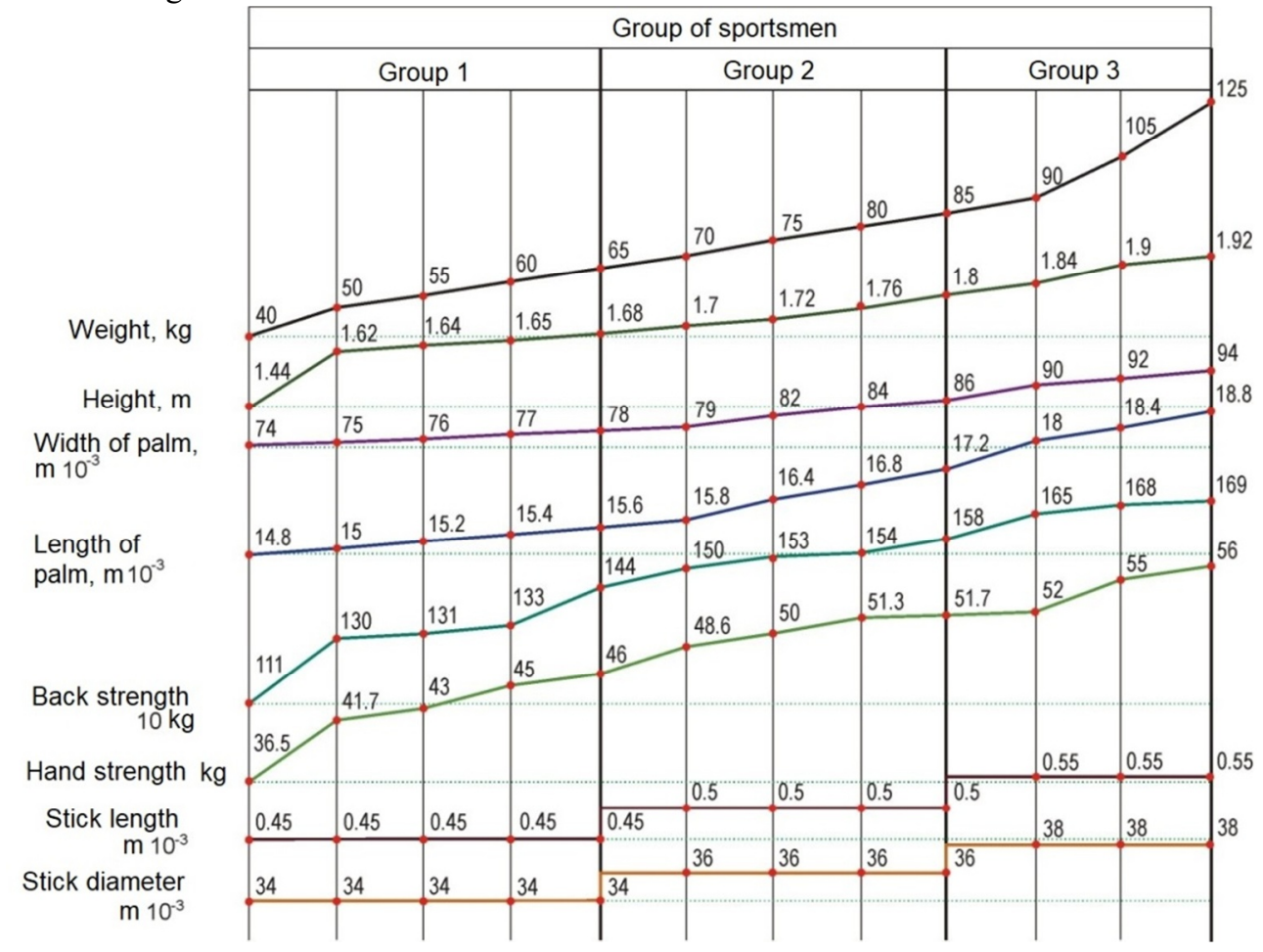

Fig. 4. Anthropometric parameters and physical development of athletes by groups

The stick is considered as a bar or a beam in a state of pure bending. The calculation of strength of beams during bending is performed according to the formula:

$$
\sigma_{\max }<[\sigma]
$$

where $\sigma_{\max }$ is the maximum normal bending stress, $[\sigma]$ is the stress accepted as the critical strength. The maximum stress is found according to the formula

$$
\sigma_{\max }=\frac{M_{\max }}{W},
$$

where $M_{\max }$ is the maximum bending moment, $W$ is the bend resisting moment. For a circular cross section of diameter $d$, it is equal to

$$
W=\frac{\pi d^{3}}{32} .
$$


The design diagram of beam loading is made and the diagram of bending moment is plotted (Figure 2). The maximum bending moment is found to act in the middle section of loading:

$$
M_{\max }=P \cdot l,
$$

where $l=\frac{H}{2}+h+\frac{H}{2}=H+h$ is the load lever. The maximum sag of the beam is observed in its middle. To verify this data, the calculation of the moment is compared to the scheme shown in Figure5.

From formulas (1-4) we obtain: $P l<[\sigma] \frac{\pi d^{3}}{32}$, or

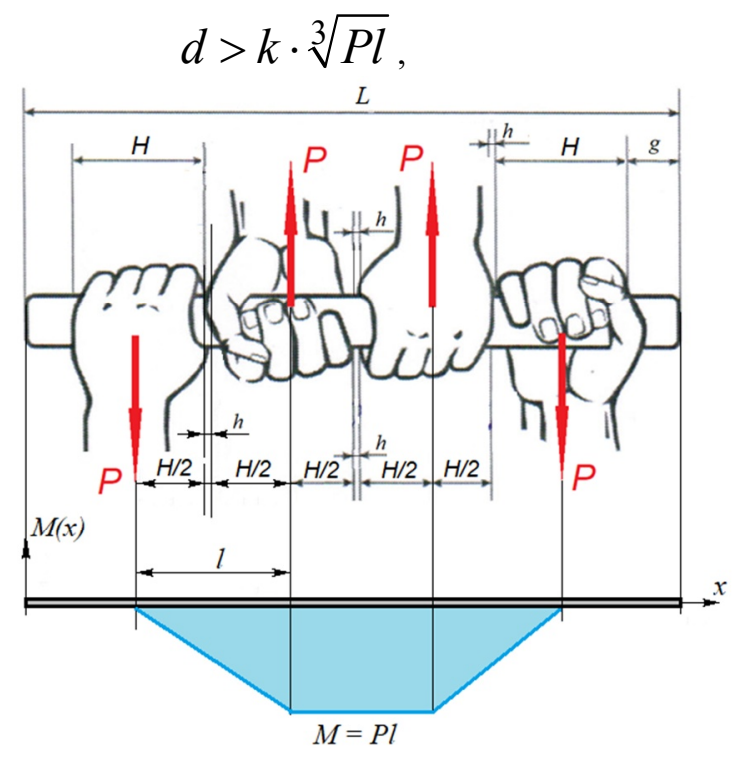

Fig. 5. Standard stick loading pattern and bending moment diagram.

where $k=\sqrt[3]{\frac{32 n}{\pi[\sigma]}}$ is the constant coefficient. The stress limit is assigned $[\sigma]$. Based on [9], the critical stress of the birch stick is taken when bending across the fibers equals $\left[\sigma_{b i r c h}\right]=97 \mathrm{MPa}$ with wood moisture of $12 \%$. It is known that with the increasing moisture content in birch its strength under static bending decreases, while being dried, it increases.

Next, the safety factor $n$ is taken and the critical stress is represented as $[\sigma]=\frac{\left[\sigma_{\text {birch }}\right]}{n}$. The safety factor $n$ is calculated as the product of separate safety coefficients taking into account different factors. At least three factors must be taken into account: inaccuracy of calculation and inaccuracy of information on the initial data $\left(n_{l}=1.2-3\right)$, heterogeneity of an inner material (knots, etc.) and of a surface $\left(n_{2}=1.2-2.3\right)$, the role of a component in the structure $\left(n_{l}=1-1.5\right)$. Then $n=n_{1} \cdot n_{2} \cdot n_{3}$. When $n_{1}=2, n_{2}=2, n_{3}=1.5$ than $n=$ 
6. The coefficient $k$ is calculated according to a formula $k=\sqrt[3]{\frac{32 n}{\pi\left[\sigma_{\text {birch }}\right]}}$. The value $k \cdot \sqrt[3]{P l}$ in formula (5) is the minimum diameter $d_{\min }$.

Along with the standard gripping of a stick, the maximum load scheme is to be considered, when one wrestler holds the stick by the very ends and another - by the very middle, without a gap between the hands (Figure 6).

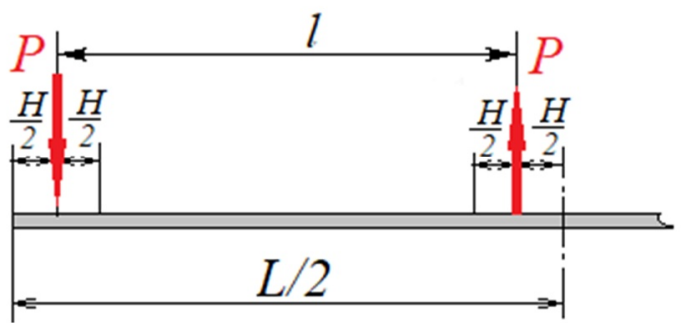

Fig. 6. Maximum load scheme.

Then the loading lever will be maximum and equal

$$
l=\frac{L}{2}-\frac{H}{2}-\frac{H}{2}=0,5 L-H .
$$

Accordingly, the value $d_{\text {min }}$ will be greater. Then certain constrains are introduced. The maximum bending moment will be greater if one wrestler holds the stick by the very ends, and another - by the middle without a gap between the hands.

To calculate the minimum diameter $d_{\min }$ for 12 categories of wrestlers in two cases of loading, a roddiam program in the environment of computer simulation MatLab is created. The initial data are introduced: arrays of values of the width $H$ of a hand and of back strength values $P$, an array of values of the stick length $L$, the gap $h$, the reserve factor $n$. All lengths are expressed in meters, force - in Newtons $(1 \mathrm{kgf}=9.80665 \mathrm{~N})$, values of the minimum diameter are expressed in millimeters.

Arrays of calculated values of the minimum diameter with a standard grip are obtained:

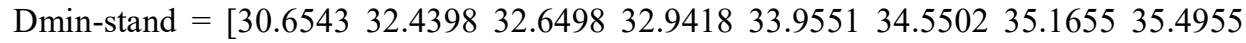
$36.052337 .078237 .548637 .8672]$

and under stressed gripping:

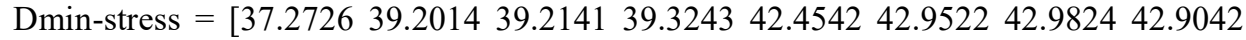
$43.098045 .517245 .625845 .5490]$

The calculation results are presented in Figure 6.

Thus, $d_{\min }$ of the stick is taken for the 1 st group of athletes equaling $34 \mathrm{~mm}$, for the 2nd $-36 \mathrm{~mm}$ and for the $3 \mathrm{rd}-38 \mathrm{~mm}$, which provides sufficient strength for each of those groups.

The effect of roughness of equipment made of different materials on sportsmen's injuries was investigated during the World Mas-Wrestling Championship 2018. The research results are presented in Table 2 and Figure 8. 


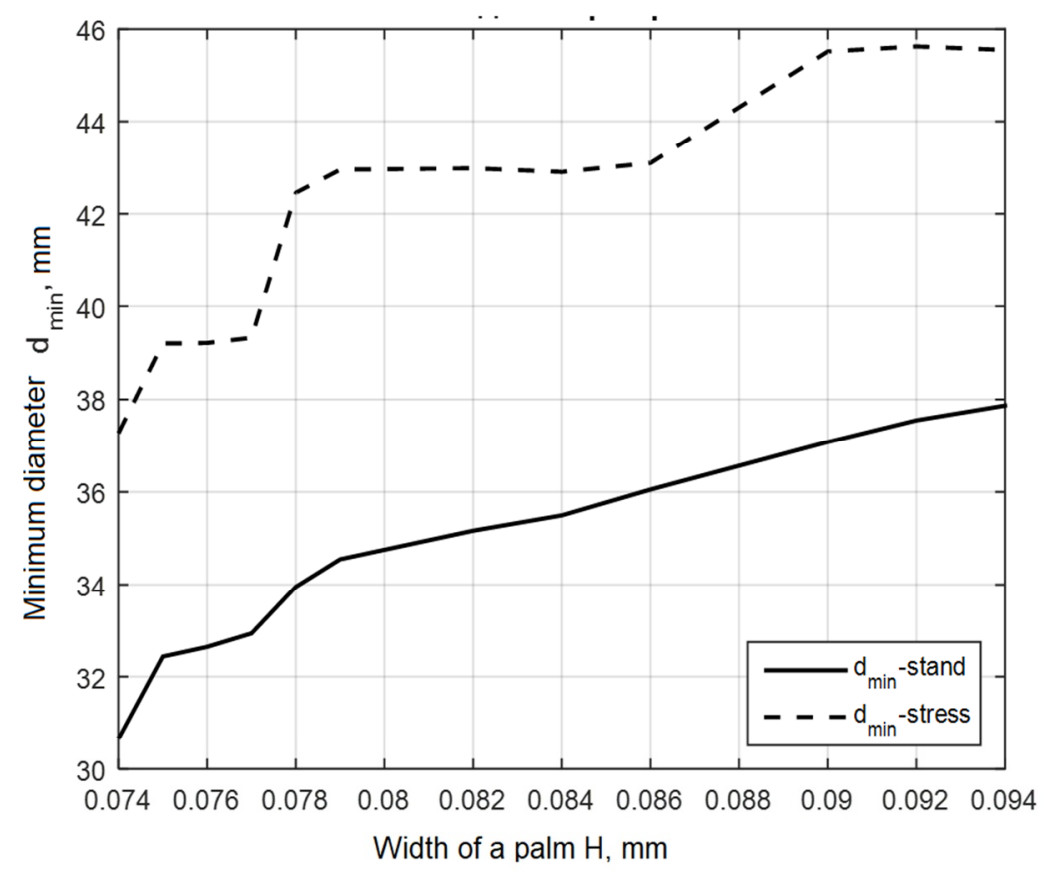

Fig. 7. The minimum diameter of birch sticks for 3 groups of athletes.

Table 2. Effect of roughness of sticks made of different materials on the skin of sportsmen's palms.

\begin{tabular}{|c|c|c|c|c|c|c|c|c|}
\hline \multirow{2}{*}{ № } & \multirow{2}{*}{$\begin{array}{l}\text { Manufacturing } \\
\text { country }\end{array}$} & \multirow{2}{*}{$\begin{array}{l}\text { Material of } \\
\text { equipment }\end{array}$} & \multicolumn{3}{|c|}{$\begin{array}{c}\text { Roughness parameters, } \\
\text { um }\end{array}$} & \multicolumn{3}{|c|}{ Palm injuries, number of athletes } \\
\hline & & & $R p$ & $R k$ & $R v$ & $\begin{array}{l}\text { Micro- } \\
\text { splinters }\end{array}$ & Scratches & $\begin{array}{l}\text { Callous } \\
\text { rip-off }\end{array}$ \\
\hline 1 & Russia & Birch & 6.3 & 8.0 & 16 & 2 & 3 & 13 \\
\hline 2 & Azerbaijan & Oak & 16 & 16 & 100 & 12 & 18 & 42 \\
\hline 3 & India & Amaranth & 12.5 & 16 & 100 & 13 & 15 & 37 \\
\hline 4 & Georgia & Linden & 6.3 & 16 & 32 & 7 & 9 & 24 \\
\hline 5 & Turkey & Hazel & 6.3 & 12.5 & 20 & 5 & 6 & 18 \\
\hline
\end{tabular}

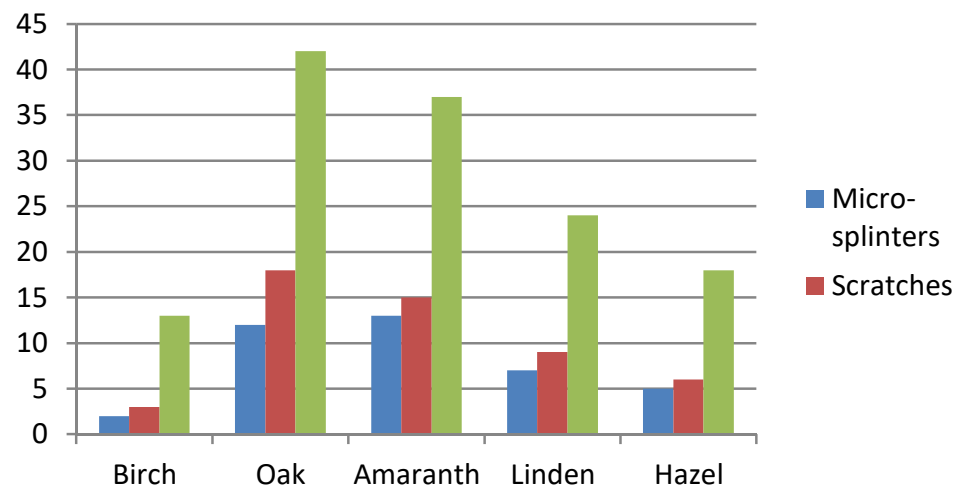

Fig. 8. Injury to athlete's palm depending on roughness of equipment - sticks and on material 
To study the roughness, profile records were taken by a profile testing instrument of type 252. This device is designed to measure roughness with digital indication. Measurement deviation is $\pm 0.1 \mu \mathrm{m}$. Figure 8 shows the height of irregularities on the material profile - wood of values $R p, R k, R v[15]$,

where:

$R p$ is the distance from the highest point of the largest protrusion of the profile to the line of single protrusions within the base length.

$R k$ is the distance from the line of single protrusions to the line of single cavities within the base length.

$R v$ is the distance from the line of single cavities to the lowest point of the deepest cavity of the profile within the base length.

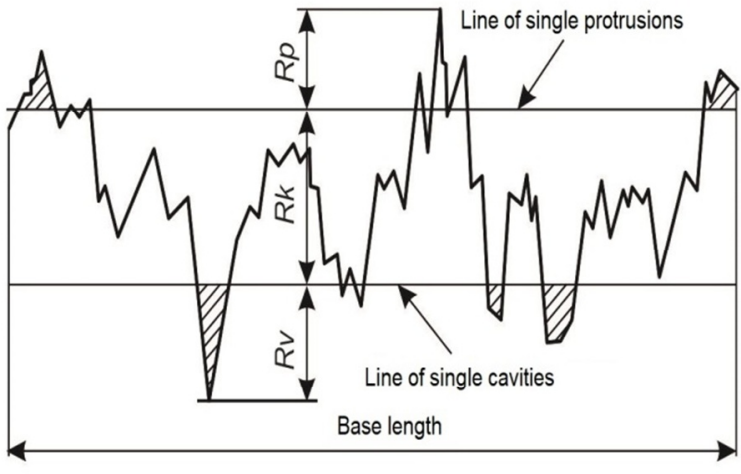

$a$

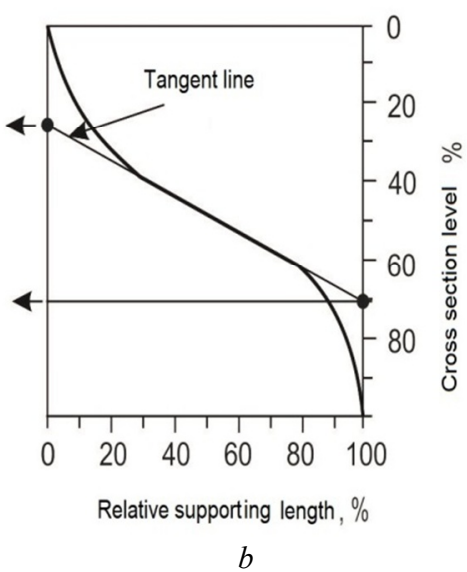

$b$

Fig. 9. Height of profile irregularities: $a$ - profile record; $b$ - relative supporting curve

The study educed that equipment made of birch causes the least number of injuries to sportsmen's palms during combats: micro-splinters were received by 2 athletes, scratches 3 athletes, callous rip-off -13 athletes.

13 sportsmen sustained the greatest number of micro-splinters using sticks made of amaranth. 18 sportsmen sustained the greatest number of scratches and 42 sportsmen got their callouses ripped off when using sticks made of oak.

\section{Results and discussion}

The study results revealed the following shortcomings of the equipment - the stick TU 9616-001-97548408-2013 in terms of physical and mechanical, ergonomic and aesthetic requirements:

- the applied design of the equipment is non-ergonomic and non-functional, which entails injuries got by sportsmen;

- significant number of athletes injure their hands, particularly palm skin by getting micro-splinters, scratches and callous rip-off due to low physical and mechanical properties of materials, in particular high surface roughness that in turn can cause more serious infectious diseases if athletes do not maintain personal hygiene.

- controversial moments arise for athletes of a lightweight category due to excessive length of the equipment - the stick hits the rest board with its ends, so that one of athletes pulls it using the forbidden "lever method"; 
The results of the study on physical and mechanical properties, roughness indices and quality of processing enabled determining that birch has the best characteristics as a material for producing the equipment - the stick for mas-wrestling.

According to interrelation of the average width, length and strength of a hand, back strength depending on height and weight of athletes, the corresponding length of the stick and its diameter were established. The classification of athletes by groups depending on their weight category and anthropometric parameters is proposed.

To increase the efficiency of mas-wrestling trainings and competitions and ensure their safety, it is proposed to change the size of the equipment - the length and diameter of the stick in accordance with anthropometric characteristics of athletes belonging to each weight category, regardless of age group.

\section{Conclusion}

The results of the study allowed elaborating the equipment - the stick for mas-wrestling that possesses high aesthetic and operational characteristics. This may solve the economic issue of preserving equipment, the problem of sustaining such injuries as palm callous ripoff, scratches and micro-splinters, as well as the problem of controversial moments during combats, which will ensure the highest organizational level of competitions.

\section{References}

1. V. Abramova, Mezhdunarodnaya nauchno-prakticheskaya konferentsiya $v$ ramkakh III Chempionata Mira po mas-restlingu «Mas-resling kak vid silovogo yedinoborstva: stanovleniye, razvitiye i populyarizatsiya», 97-102 (2018)

2. D. Baisheva, L. Zhukova, J.Diz, Mat. Tech 1(53), 46-51 (2019)

3. W. Ellis, Molecular Crystals and Liquid Crystals 353, 75-84 (2000). DOI:10.1080/10587250008025649.

4. G. Ellis, B. Yaman, S. Ozden, S. Donmez, Sains Malaysiana 42(5), 547-552 (2013).

5. L. Zhukova, Mezhdunarodnaya nauchno-prakticheskaya konferentsiya $v$ ramkakh III Chempionata Mira po mas-restlingu «Mas-resling kak vid silovogo yedinoborstva: stanovleniye, razvitiye i populyarizatsiya», 454-462 (2018)

6. V. Kislyy, P. Shcheglov, Spravochnoye posobiye po derevoobrabotke (Yekaterinburg, AO "BRIZ", 1995)

7. G. Pisarenko, A. Yakovlev, V. Matveyev, Spravochnik po soprotivleniyu materialov (Kiyev, Naukova Dumka, 1988)

8. I. Pis'menskiy, Fizicheskaya kul'tura (Moscow, Yurayt, 2014)

9. A. Reshin, Predel prochnosti berezy pri staticheskom izgibe (Bryansk, Bryansk. gos. tekhnol. akad., 2015).

10. J. J. Crisco, R.M. Greenwald, J.D. Blume, L. H. Penna, Medicine and Science in Sports and Exercise 34(10), 1675-1684 (2002). DOI:10.1097/00005768-200210000-00021.

11. M. Sommer, M. Passler, R. Schledjewski, Kunststoffe-Plast Europe 94(5), 89-91 (2004).

12. V Feodos'yev, Soprotivleniye materialov: uchebnik dlya vuzov (Moscow, Izd-vo MGTU im. N. E. Baumana, 2016) 
13. The Law "On the Strategy for the Socio-Economic Development of the Republic of Sakha (Yakutia) until 2032 with a targeted vision until 2050", approved on 12.19.2018, 2077-3 № 45-VI.

14. Federal Agency for Technical Regulation and Metrology, Earth-digging machinery. Anthropometric data of operators and the minimum working space around the operator. GOST R ISO 3411-2011 (M., Standartinform, 2013)

15. Federal Agency for Technical Regulation and Metrology, Wood products and wood materials. Surface roughness parameters. GOST 7016-2013. (M., Standartinform, 2014) 